\title{
GÊNERO E VIOLÊNCIA SIMBÓLICA: UM ESTUDO INTRODUTÓRIO SOBRE O SER DA MULHER E OS PAPÉIS CONSTRUÍDOS EM SOCIEDADE
}

\author{
GÉNERO Y VIOLENCIA SIMBÓLICA: UN ESTUDIO INTRODUCTORIO SOBRE EL SER DE LA \\ MUJER Y LOS PAPELES CONSTRUIDOS EN SOCIEDAD
}

\author{
Agnaldo Paulino Ferreira Júnior ${ }^{*}$
}

\begin{abstract}
RESUMO
Este estudo busca analisar o papel da mulher na sociedade moderna e meados da Idade Contemporânea no que diz respeito ao estado de ser mulher. Embasados em pontos de vista histórico-analíticos, faz-se necessário analisar os aspectos históricos das épocas em questão, para assim poder entender o local (social) no qual as mulheres foram inseridas. Entendendo o papel da mulher como uma forma de alienação conjugal, social e política, que visava o empoderamento patriarcal em detrimento de uma submissão feminina, este estudo também tem a finalidade de demonstrar a violência simbólica constituída a partir de caracteres não materiais, mas através de discursos e enculturamento arbitrariamente sexistas. Será possível considerar, como já falado por tantos autores, que não existem diferenças corporais ou intelectuais que coloquem a mulher em situação de sujeição? O lugar do bode expiatório poderia ser atribuído a qualquer grupo na tentativa de "minimizar" ou "justificar" as tensões e incertezas da não possibilidade de realização de desejo de outros grupos? Tendo essas questões postas, de maneira introdutória, espera-se que este estudo possa contribuir no adensamento das ações de enfrentamento relacionadas à violência simbólica e de gênero.

PALAVRAS-CHAVE: Violência simbólica. Feminismo. Gênero. Contrato sexual.
\end{abstract}

\section{RESUMEN}

Ese estudio busca analizar el papel de la mujer en la sociedad Moderna y meados de la Edad Contemporánea en lo que concierne al estado de ser mujer. Embazados en puntos de vista histórico analítico, se hace necesario analizar los aspectos históricos de las épocas en cuestión, para que así se pueda comprender el local (social) en la cual las mujeres fueron inseridas. Entendiendo el papel de la mujer como una manera de alienación conyugal, social y política que visaba el empoderamiento patriarcal en detrimento de un sometimiento femenino, ese estudio también tiene la finalidad de demostrar la violencia simbólica constituida a partir de caracteres no materiales, pero a través de discursos y enculturamiento arbitrariamente sexistas. Es posible considerar, como ya hablado por muchos autores, que no existen diferencias corporales o intelectuales que ponen la mujer en situación de sujeción. El lugar del "chivo expiatorio" podría ser atribuido a cualquier grupo en la tentativa de minimizar o justificar las tensiones e incertidumbres de los grupos de la imposibilidad de realización de deseo de otros grupos. Teniendo en cuenta esas cuestiones puestas, de manera introductoria, es de esperar que ese estudio pueda contribuir en el adensamiento de las acciones de enfrentamiento relacionadas a la violencia simbólica y de género.

PALABRAS CLAVES: Violencia simbólica. Feminismo. Género. Contrato sexual.

\footnotetext{
* Mestrando em Filosofia Antiga e Medieval pela UFMG. Graduado em filosofia (Instituto Santo Tomás de Aquino) e em administração (Faculdade Marista Recife). Bolsista no Projeto Coleção Terras de Quilombos, no núcleo de estudos e projetos de ciências políticas da UFMG. E-mail: agnaldodiunizio@yahoo.com.br.
} 
Ninguém nasce mulher: torna-se mulher. Nenhum destino biológico, psíquico, econômico define a forma que a fêmea humana assume no seio da sociedade; é o conjunto da civilização que elabora esse produto intermediário entre o macho e o castrado que qualificam de feminino.

(BEAUVOIR, 1967, p. 9).

A questão do ser da mulher e o papel exercido por ela (ao menos sobre o que se tem escrito) nas esferas da sociedade já é algo discutido, ou pelo menos comentado, desde os primórdios da Grécia Antiga. Entretanto, foi na modernidade e contemporaneidade que essa questão passou a ter mais visibilidade com os filósofos e pensadores contratualistas como Rousseau, Husserl e Kant, bem como os movimentos feministas criados a partir do século $\mathrm{XX}^{1}$.

Tratar de um tema tão extenso em tão poucas linhas, visto toda a bibliografia já produzida sobre ele, as discussões acadêmicas e sociais, não é uma tarefa das mais fáceis; bem como o assunto é cheio de nuances, interpretações e controversas. Não é intenção deste estudo salientar ou entender as questões relacionadas à violência de gênero a partir da distinção de culpados ou inocentes, mas debruçar sobre um assunto que há muito vem sendo discutido na tentativa da permanência das discussões, possibilitando novas formas de ideias e opiniões que contribuam para a luta e enfrentamento das questões relativas à violência de gênero.

Que existem ideias de uma "inferioridade" do ser feminino em relação ao ser masculino, isso já se sabe. Mas em que momento tal prerrogativa foi inserida no modo de ser, pensar e viver dos homens e das mulheres isso não é possível precisar. Já em Hesíodo, no poema Teogonia, temos a história que conta a criação do ser Feminino. No reinado de Cronos os homens viviam como os deuses. Zeus, ao vencer a guerra contra Cronos, seu pai, faz com que os homens passem a viver uma vida temporal, o que nasce tende à morte. Prometeu, como um defensor da humanidade, rouba sementes de fogo de Héstia e as entrega aos homens. Irritado, Zeus condena Prometeu a ter seu fígado devorado por Ethon, uma águia, todos os dias no monte Caucaso, enquanto se regenerava à noite. Por solicitação de Zeus, Hefesto e Atena dão origem a Pandora, a primeira mulher que é dada a Epimeteu, irmão de Prometeu, como presente. É dela, narra Hesíodo (1995, p. 106), que “[...] descende a geração das femininas mulheres. Dela é a funesta geração e grei das mulheres, grande pena que habita entre homens mortais".

Por uma necessidade de perpetuação da espécie, Zeus cria a mulher, visto a não mais imortalidade dos homens. Mas a visão do ser de Pandora, ainda sim, traz consigo o caráter negativo dos males que do jarro são soltos. Assim como também é possível interpretar que o

\footnotetext{
1 Angela Davis (2016) traz fatos históricos que demonstram a força das mulheres na luta pelo direito de igualdade de gênero (pensando gênero como papel em sociedade) e na luta contra o regime escravagista.
} 
surgimento do homem é anterior e superior ao da mulher, dado que eles viviam como os deuses, e a mulher já surge em condição de mortalidade.

\title{
ENTENDENDO O CONTRATO SOCIAL
}

Não é possível precisar quando a ideia de feminilidade foi considerada inferior em relação à masculinidade, mas tal ideia foi levada adiante de modo a ser encontrada tal concepção nos pensadores contratualistas, como Carole Pateman busca mostrar em seu livro O contrato sexual (1995). Neste a autora elabora uma série de argumentos que demonstram a visão de inferioridade que alguns pensadores possuem em relação ao ser da mulher. Para isso, ela utiliza o argumento dos filósofos que afirmam ou criticam o contrato social e suas particularidades no que diz respeito a elaboração do contrato.

Para pensar o contrato social é necessário compreender que ele só pode se dar entre seres sociais políticos naturalmente livres e iguais. Como definirá Rousseau (2010, p. 24):

\begin{abstract}
Encontrar uma forma de associação que defenda e proteja de toda a força comum a pessoa e os bens de cada associado, e pela qual, cada um, unindo-se a todos, não obedeça portanto senão a si mesmo, e permaneça tão livre como anteriormente [...] as cláusulas deste contrato são de tal modo determinadas pela natureza do ato, que a menor modificação as tornaria vãs e de nenhum efeito; de sorte que, conquanto jamais tenham sido formalmente enunciadas, são as mesmas em todas as partes, em todas as partes tacitamente admitidas e reconhecidas, até que, violado o pacto social, reentra cada qual em seus primeiros direitos e retoma a liberdade natural, perdendo a liberdade convencional pela qual ele aqui renunciou.
\end{abstract}

Pensando em contrato social, é clara a ideia de que, para existir um contrato formalizado, é necessário que ele esteja definido entre limites de igualdade entre contratante e contratado. Uma relação na qual os dois integrantes do contrato têm liberdade para oferecer, em troca, e de maneira justa, aquilo que possuem. E, em caso de uma das partes se sentir lesada, o contrato pode ser desfeito, voltando as duas partes ao estado de liberdade que possuíam antes, deixando assim o estado de dominação e subordinação.

Pateman não discorda dessa visão do contrato. Para ela tal visão é revolucionária no que diz respeito às reinvindicações do indivíduo. Mas na prática a teoria não se aplicava dessa maneira. Como a dominação de alguns em relação à subordinação de muitos não estava mais pautada na vontade divina, os "[...] conservadores de todos os tipos tiveram medo de que essa situação se tornasse realidade e de que a teoria se tornasse, por conseguinte, nociva à ordem social" (PATEMAN, 1995, p. 67). 
A preocupação de uma possível desordem baseada na possibilidade de uma insujeição impulsiva, que entendia a obediência como mera convenção, fez com que os dominantes percebessem que era viável o que Pateman chamará de paradigma da obrigação voluntária.

O contrato sexual no que diz respeito a sua teoria, parecia perfeito, ao menos para os que buscavam certa igualdade nas relações de submissão voluntária que visavam a manutenção da vida de ambas as partes. Mas na prática a relação não se mostrou tão igualitária assim. Que os homens eram ou se tornaram livres com essa nova versão do contrato isso pode-se entender, mas havia uma condição que deturpava essa nova forma de pensar.

Quando se volta para as relações do trabalho é possível identificar que existem mais empregados que patrões. Portanto, mais subordinados que dominadores, com a mão de obra mais abundante que a escassez dos contratantes. Estes perceberam o poder de barganha que tinham em relação àqueles. A não aceitação do acordo por parte do contratado levaria ao rompimento do contrato, que ocasionaria outra contratação para aquele serviço. Desse modo, sempre quem sai perdendo é o contratado visto a pouca quantidade de contratantes.

\section{RELAÇÃO DOMINAÇÃO VERSUS SUBMISSÃO}

A relação dominador/submisso não se dá apenas no ambiente de trabalho. Pierre Bourdieu em seu livro A dominação masculina menciona uma breve história que permite perceber essa relação díspar de poder dominação/submissão também nas relações sexuais.

Foi na fonte que o primeiro homem encontrou a primeira mulher. Ela estava
apanhando água quando o homem, arrogante, aproximou-se e pediu de beber. Mas
ela havia chegado primeiro e também estava com sede. Descontente, o homem a
empurrou. Ela deu um passo em falso e caiu por terra. Então, o homem viu as coxas
da mulher, que eram diferentes das suas. E ficou paralisado de espanto. A mulher,
mais astuciosa, ensinou-lhe muitas coisas: 'Deita-te, disse ela, e eu te direi para que
servem teus órgãos'. Ele se estendeu por terra. [...] e deitou-se sobre ele. O homem
experimentou um prazer enorme [...] Um dia, o homem disse à mulher: 'Eu quero te
mostrar que eu também sei fazer coisas. Estende-te e eu me deitarei sobre ti.' A
mulher deitou sobre a terra e o homem se deitou sobre ela. E ele sentiu o mesmo
prazer. E então disse à mulher: 'Na fonte és tu (quem dominas), na casa sou eu'[...].
(BOURDIEU, 2012, p. 34-35).

É clara a ideia de uma relação dominador/submisso em algumas áreas do convívio social bem como, a partir do conto elaborado por Bourdieu, a ideia dessa relação também na vida entre quatro paredes da relação matrimonial. Esta é a intenção deste estudo: buscar 
entender o papel social da mulher como o sexo frágil, submisso, e o homem na relação de superioridade e dominação.

Tanto na poesia de Hesíodo quanto no conto de Pierre Bourdieu o papel atribuído à mulher possui uma conotação negativa e/ou inferior ${ }^{3}$. Mas como geralmente o conto é utilizado para relatar um problema ou uma situação social, ele apenas serviu para refletir uma visão de algo que já acontecia, como fenômeno, nos aspectos antropológicos da vivência de algumas culturas ${ }^{4}$.

São inúmeros os motivos utilizados que defendiam a submissão feminina em contraposição à dominação masculina. Os órgãos genitais se tornaram fontes de reflexão e entendimento do homem como possuidor da força, da majestade, da coragem e da razão (SOIHET, 1997) por possuir genitálias que o elevavam para o alto, num momento de ruptura crescente e que o tornam um ser de sociabilidade cujas assembleias, mercados e salas de estar são locais onde se faz necessária a sua presença (BOURDIEU, 2012).

Já as mulheres, com uma genitália mais introspectiva, são fonte incessante de graça, beleza, fineza e sentimentos (SOIHET, 1997) que deveriam ser mantidas em lugares mais reclusos, evitando assim seu desgaste pela euforia e desordem da vida social que só o homem com sua "brutalidade" poderia suportar. Para melhor compreender essa ideia, Angela Davis (2016, p. 31) narra o seguinte exemplo de perfeição feminina do século XIX: "na imprensa, na literatura popular e na lei, a mulher era retratada como sendo mulher perfeita se fosse mãe perfeita. O seu lugar era em casa - nunca, claro, na esfera política".

À mulher é dado o interior da vida conjugal. Todas as suas atitudes devem refletir o estado de passividade observado já no ato sexual ${ }^{5}$ e que deve ser engendrado na vida social

\footnotetext{
${ }^{2}$ Aqui é usado o verbo atribuir, em detrimento do verbo "assumir", por entender que o papel desempenhado pela mulher é uma construção social imposta ou pensada de maneira a subjugá-la a posições inferiores na vida social e em tudo que diz respeito aos contratos sociais e sexuais.

${ }^{3}$ Mulheres negras, em países de regime escravocrata, eram vistas como mão de obra e só depois entendidas como mulheres, donas de casa e mães de família (DAVIS. 2016).

${ }^{4}$ Importante deixar claro que não são todas as culturas que entendem o papel social da mulher como frágil ou um papel social de submissão. Pierre Bourdieu (2012) traz alguns exemplos de culturas nas quais a mulher possui um papel social e sexual tão importante quanto o homem.

${ }^{5}$ Simone de Beauvoir analisa biologicamente a relação sexual, bem como as reações que envolvem o corpo, mais especificamente, as regiões erógenas (órgãos sexuais) do homem e da mulher. A mulher se mantém longe dessa passividade sexual. Para uma relação sexual de reciprocidade, na mulher é necessária a produção de "[...] fenômenos positivos em seu organismo: inervação das zonas erógenas, intumescência de certos tecidos erécteis, secreções, elevação da temperatura, aceleração do pulso e da respiração" (BEAUVOIR, 1967, p. 116). O que, de maneira distinta, também caracteriza uma atividade sexual e não passividade. A análise sexual de Beauvoir permite enxergar que nem mesmo o ato sexual, que é analisado por alguns autores como empoderamento do homem sobre a mulher no sentido da realização da atividade daquele e da inércia da passividade desta, serve para simular ou possibilitar o entendimento da submissão da mulher no sexo conjugal, na família ou na esfera social.
} 
pelo comportamento, vestimenta, modo de falar e até mesmo de pensar. A passividade atribuída não permite à mulher qualquer tipo de atividade que a liberte do estado de inércia que compreende sua vida sexual, familiar e social ${ }^{6}$.

Toda essa ideologia apenas corrobora uma submissão do feminino em relação ao masculino, caracterizando uma espécie de agressão moral ou social qualquer possibilidade de inversão desse sistema. Pierre Bourdieu (2012, p. 7-8) chamará esse emaranhado de pensamentos que se desenrolam na dialética do interior e do exterior - da sensibilidade e razão e da passividade e da atividade - de violência simbólica, que definirá da seguinte maneira:

Violência simbólica, violência suave, insensível, invisível a suas próprias vítimas, que se exerce essencialmente pelas vias puramente simbólicas da comunicação e do conhecimento, ou, mais precisamente, do desconhecimento, do reconhecimento, ou, em última instância, do sentimento.

Violência simbólica, violência social, violência moral são alguns dos possíveis nomes, que esse tipo de atividade, que visa a submissão de um ser cuja realidade passa pelo desconhecimento de conceitos e afirmações erigidas em vista da conquista do poder e dominação social, pode compreender.

As mulheres são tratadas não como sujeito mas como uma coisa, buscando-se impedir a sua fala e a sua atividade. "Nesta perspectiva, a violência não se resume a atos de agressão física, decorrendo igualmente, de uma normatização na cultura, da discriminação e submissão feminina". (SOIHET, 1997, p, 10).

\section{A ESCRAVIDÃO NA VIDA CONJUGAL}

A família patriarcal moderna pode ser exemplificada a partir da narrativa de Carole Pateman (1995) na perspectiva de uma pirâmide dividida em três partes, cujas decisões são sempre verticais e descensionais. Nesse modelo o homem se encontra no cume da pirâmide, sendo ele quem decide como funcionam os dois níveis abaixo, que compreendem a mulher e

\footnotetext{
${ }^{6}$ Ainda é possível entender no pensamento de Beauvoir que a saída da inércia para a libertação e apropriação da atividade é também comprometida pelo comportamento da mulher quando em suas aparições sociais. "Para significar que há festa, isto é, luxo e desperdício, esses vestidos devem ser caros e frágeis, tão incômodos quanto possível; as saias são tão compridas, tão largas ou tão estreitas que atrapalham o andar; por baixo das joias, das anáguas, das lantejoulas, das flores, das plumas, das perucas, a mulher é transformada em boneca de carne [...]" (BEAUVOIR, 1967, p. 229). Vista como um objeto a ser usado pelo homem a seu próprio modo e gosto, qualquer excesso, extrapolação ou desvio do plano socialmente perfeito construído para a mulher, dos anos 1950 (período aproximado da publicação do livro O segundo sexo, de Simone de Beauvoir), é considerado subversivo, $\mathrm{e}$ as atividades um atributo da homossexualidade feminina.
} 
filhos na parte central, dando forma e aparência, características necessárias ao empoderamento da vida social, e escravos, aprendizes e serventes na base, seres necessários à sustentação e manutenção das áreas acima.

As duas partes abaixo do cume estão ligadas propositalmente como servidores do amo, do senhor, do homem da casa. A esposa, mesmo possuindo características que a tornariam um ser livre, é condicionada ao papel de serva (aquela que serve ao) do esposo.

Desde as civilizações primitivas até os nossos dias sempre se admitiu que a cama era para a mulher um "serviço" que o homem agradece com presentes ou assegurandolhe a manutenção: mas servir é ter um senhor; não há nessa relação nenhuma reciprocidade. (BEAUVOIR, 1967, p, 112).

Rousseau (2010, p. 15) define a escravidão como uma espécie de alienação; “alienar é dar ou vender". Aquele que se aliena, se escraviza, o faz com o intuito de receber algo em troca, podendo ser esse algo a sua própria subsistência. O ser, ao alienar-se, entrega todos os seus direitos de liberdade natural ao seu mantenedor, tornando-se um objeto sem vontade própria, um ser passivo, submisso e inerte.

Como membro das partes inferiores da pirâmide, a mulher também se percebe inserida nesse âmbito dos seres sem direito e sem liberdade natural. $\mathrm{O}$ casamento passa a ser percebido como um contrato de alienação sexual, conjugal e político. Essa ideia é exposta na seguinte narrativa de Angela Davis (2016, p. 32):

\begin{abstract}
As mulheres brancas do norte - as donas de casa de classe média também conhecidas como as novas "mill girl" (operárias) - frequentemente invocavam a metáfora da escravatura quando pensavam as suas respectivas opressões. As mulheres bem posicionadas começaram a denunciar a sua falta de preenchimento da sua vida doméstica e definiam o casamento como uma forma de escravatura.
\end{abstract}

Com o advento da metalurgia e do capitalismo, as mulheres começaram a se inserir no mercado de trabalho, porém, a relação de submissão vivenciada em casa também foi transmitida à vida pública e profissional, se é que se pode chamar de profissional as condições empregatícias oferecidas às mulheres durante os primeiros 50 anos do século $\mathrm{XX}^{7}$.

A relação contratual entre seres naturalmente livres se dá a partir da troca de serviço versus remuneração ou subsistência. Mas como já foi possível ver anteriormente, as relações

\footnotetext{
${ }^{7} \mathrm{O}$ filme Daens do Dir. Stijn Coninx mostra as condições de trabalho durante os primeiros anos do século XX, com o advento do capitalismo e as novas formas econômicas do setor secundário europeu, bem como a precariedade e desigualdade da relação trabalhista no que diz respeito às diferenças salariais do homem e da mulher.
} 
que deveriam permanecer igualitárias eram passíveis de novas interpretações e desfechos. Se havia dominação e submissão na relação trabalhista entre homens iguais e livres a entrada da mulher, sem esquecer da entrada, também, das crianças no mercado de trabalho, que já eram considerados "naturalmente submissos", apenas acentuou esse contexto de manipulação. Mulheres e crianças como seres "naturalmente inferiores" não participavam do contrato social, não podendo assim participar efetivamente da elaboração do contrato, o que permitia a empregabilidade desses por salários relativamente baixos. Além do mais, mulheres e crianças não eram convocadas a servir seus países em períodos de guerra, o que contribuiu ainda mais para a entrada destes no mercado de trabalho durante os quarenta e um anos que se estendiam entre o início da Primeira e o fim da Segunda Guerra Mundial.

Apenas em 1948, com a elaboração da Declaração Universal dos Direitos Humanos, que buscou empreender uma relação mais equitativa tanto nas questões conjugais quanto nas questões políticas e sociais, as mulheres tiveram pela primeira vez, legislativamente oficial, direitos que empreenderiam uma relação mais igualitária dos seres, independentemente do sexo, ou gênero.

\section{CONCLUSÃO}

Ser mulher, ou adotar o papel de mulher na sociedade, mesmo a atual, não é algo tão simples de ser realizado. Desde as primeiras histórias sobre a criação dos sexos, o ser feminino sempre foi visto a partir de um olhar inferiorizado. Essa perspectiva foi se tornando ainda mais robusta e encorpada com o tempo.

A mulher se tornou um objeto da vida social e matrimonial; assim como os escravos, sua principal função era servir ao amo da casa. Para os escravos servir ao amo, para os contratados servir ao patrão, para a mulher servir ao marido. Todos em função de serventia a um mesmo homem naturalmente livre.

Em que momento se dá essa alocação da mulher no papel de serventia já foi visto que não é possível precisar, mas é bastante clara a violência, simbólica ou material, que se dá no fato de uma pessoa ser "obrigada" a adotar um determinado papel social simplesmente por ser do sexo feminino. Não é questão de fragilidade, falta de competência ou habilidade para sair do estado de inércia desse papel inferior atribuído que torna o papel da mulher tão difícil, mas a falta de oportunidade e pouca voz que ela ainda possui, mesmo com os avanços dos movimentos feministas e as leis de proteção às mulheres que visam à igualdade de direitos. 
Infelizmente são pouco mais de duzentos anos de luta, que visam defender o gênero feminino como naturalmente livre e possuidor de direitos, contra uma cultura patriarcal construída através da história, ao menos o que se tem escrita, de alguns grandes grupos da sociedade.

Hannah Arendt (1990) relaciona a violência sofrida pelos judeus com a teoria do bode expiatório. O ser humano é possuidor de desejos, e seus desejos sempre se voltam para um ser humano ou algum outro ser. A complicação se dá quando aquele possuidor de determinado desejo percebe no outro, que por sua vez é le même et l'autre, os desejos que possui. "A partir dessa amostra, é possível visualizar com que rapidez uma vontade individual pode se tornar coletiva, tendo em vista que a cobiça de um homem pode ser observada e imitada por muitos outros [...]" (FURTADO, 2013, p. 12)

O desejo coletivo de um mesmo objeto tende a gerar conflitos, discórdia, violência material ou simbólica. Mas não é o desejo que gera o conflito ou a violência e sim a frustração, a raiva ou a necessidade de eliminar e/ou controlar os impulsos e volições alheias em vista da soberania dos seus anseios em relação aos do outro. Assim como os desejos, a frustração, raiva ou controle podem ser disseminados a partir de um personagem central e individual ganhando forças na coletividade que o apoia.

O bode expiatório, representado individualmente ou em grupo, pode ser escolhido de diversas maneiras. Pichon Rivière (2005) atesta que essa escolha se dá através de um possível "fracasso" no processo de liderança; já Girard (2004) traz à luz a ideia de que a vítima para ser escolhida deve possuir características que viabilizem tal escolha ou uma relação dela com um crime que cause repulsa entre o grupo. Alguns exemplos são: o mito de criação das mulheres na Teogonia de Hesíodo e o mito de Adão e Eva narrado no livro do Gêneses da Bíblia Sagrada.

Independentemente da forma como o bode expiatório é escolhido, não existem motivos plausíveis que atestem a culpabilidade e escolha das vítimas. Seja no caso dos judeus ou das mulheres, qualquer grupo, ou qualquer pessoa poderia assumir o lugar do bode expiatório, o que atesta, com rigor, a violência simbólica ou material de um grupo opressor em relação a um grupo submisso.

Mesmo com os inúmeros progressos das lutas feministas, ainda é possível visualizar que tal ideologia deve permanecer forte em busca de direitos que visem à igualdade entre os iguais e que estes sejam tratados de maneira diferente em suas particularidades, não havendo assim distinção de direitos entre os seres humanos. 


\section{REFERÊNCIAS}

ARENDT, Hannah. Origens do totalitarismo. São Paulo: Companhia das Letras, 1990.

BEAUVOIR, Simone de. O segundo sexo: a experiência vivida. São Paulo: Difusão Europeia de Livros, 1967.

BOURDIEU, Pierre. A dominação masculina. Tradução de Maria Helena Kühner. 11. ed. Rio de Janeiro: Bertrand Brasil, 2012.

DAENS: um grito de justiça. Dir. Stijn Coninx. Perf. Louis Paul Boon. Favourite Films, Investco \& Kredietbank Luxemburg. 1992.

DAVIS, Angela. Mulheres, raça e classe. São Paulo: Boitempo, 2016.

FURTADO, Letícia de Souza. A teoria do bode expiatório, de René Girard, aplicada à chacina de Matupá. Porto Alegre. Trabalho de conclusão de curso (Monografia). Pontifícia Universidade Católica do Rio Grande do Sul, RS. 2013.

GIRARD, René. O bode expiatório. Tradução de Ivo Storniolo. São Paulo: Paulus, 2004.

HESIODO. Teogonia: a origem dos deuses. Tradução de Jaa Torrano. São Paulo: Editora Iluminuras Ltda, 1995.

PATEMAN, Carole. El contrato sexual. Barcelona: Anthropos; México: Universidad Autónoma Metropolitan, Iztapalapa. 1995.

RIVIÈRE, Pichon. O processo grupal. São Paulo: Martins Fontes. 2005.

ROUSSEAU, Jean Jacques. O contrato social. Tradução de Mário Franco de Souza. Oeiras, Portugal: Editorial Presença, 2010.

SOIHET, R.. Violência simbólica: saberes masculinos e representações femininas. Estudos Feministas, Rio de Janeiro, v. 5 n.1, p. 7-29, 1997. 